\title{
MONITORING AND TESTING MOTOR SKILLS IN YOUNG SOCCER PLAYERS
}

\author{
Gaetano RAIOLA ${ }^{1 *}$, Francesca D’ELIA ${ }^{1}$, Tiziana D'ISANTO², Gaetano ALTAVILLA ${ }^{3}$ \\ ${ }^{1}$ University of Salerno, Salerno, Italy \\ ${ }^{2}$ MIUR Campania, Italy \\ ${ }^{3}$ University of Split, Faculty of Kinesiology, Split, Croatia \\ *Corresponding author: graiola@unisa.it
}

DOI: 10.35189/iphm.icpesk.2019.37

\begin{abstract}
Soccer is a very popular sport all over the world. Huge economic and social interests are at stake, therefore there is a need to constantly improve game quality and player performance, above all, motor skills. The purpose of this study is to monitor and assess the reduction or improvement of performance in a sample of twelve young male soccer players aged 11-12 years. The study is useful for coaches to reorganize the training planning and adapt it to individual players. The method is experimental and involves the usual parameters for training monitoring. The data were collected during four weeks. They were expressed as average $\pm S D$ for: height (152.8 \pm 2.95$)$, weight $(44.6 \pm 2.11)$, body mass index (19.1 \pm 1.42$)$ and using some field tests (Harre's test, Precision shooting test and Ball control test). The analysis of statistical data was performed with the t-Test to check the differences between pre-test and post-test (at the beginning and the end of a month of specific training). The significant differences were fixed at $p<0.05$. The results show that there is a significant difference in performance between pre- and post-training for the three tests conducted. This study examines and assesses the reduction or improvement of performance, allowing coaches to monitor the training process.
\end{abstract}

Keywords: field tests, qualitative aspects, assessment, performance.

\section{Introduction}

Physical, motor and sport activities should be at the centre of the teaching-learning and skill-building processes (Fisher et al., 2005). In the field of physical activity and sports (Raiola, 2012), it is essential to identify methodologies that facilitate participation in terms of adequate quantity and learning (Serrano, Shahidian, Sampaio, \& Leite, 2013). Determining what methodology is most effective for motor learning (Altavilla, Tafuri, \& Raiola, 2014) means allowing coaches to schedule workouts so that they can have a positive impact on performance and therefore on the final result of each match (Raiola \& Rago, 2014). Sport activities, such as soccer, include all the educational and training features required for the development of young athletes. In soccer, there are many rules and many physical, technical and tactical skills (Dellal et al., 2011) to be mastered, monitored and tested through specific tests. It is widespread in sport to test one or more athletes for several reasons: above all, this allows assessing their potential, their athletic and technical qualities (Safrit, 1990), for example, for a particular skill needed during an intensive sports game such as soccer: rapidity, agility or coordination skills (Mathisen \& Danielsen, 2014), but also setting up a correct training methodology to verify and monitor the effectiveness of training and changes in physical condition (Hughes \& Bartlett, 2002).

For both the coach and the athlete, it is very important to regularly monitor the results of the training programmes (Polidoro, Bianchi, Di Tore, \& Raiola, 2013).

Tests are a fundamental periodic control tool (Cirillo, Nughes, Acanfora, Altavilla, \& D'Isanto, 2016). They are very effective also due to the result analysis and the feedback received, which makes it possible to relate performance to working strategies, and thus identify and make the best adjustments to the training programmes (Chiodera et al., 2008).

This study involves the use of the following three tests: Dexterity circuit (Harre), Precision shooting and Ball control, which are easy to administer and able to detect the qualitative abilities of young soccer players. The tests used were chosen for their simplicity of execution, effectiveness and ease of finding the material needed. Data collection was carried out in the same training session, and this was repeated after one month to be able to assess possible improvements.

The aim of the study is to test and assess motor skills and technical skills in soccer players by monitoring the effects induced by 4 weeks of specific training.

\section{Material and Methods}

The study method is experimental, and the data were collected from three tests (a general test and two specific tests), before and after 4 weeks of specific training. During this period, players mainly performed three types of 
exercises (three times per week): 6 vs. 6 games with up to two ball touches (30 min), circuits or exercises for the coordination skills (30 $\mathrm{min}$ ) and exercises for the individual technique such as dribble, pass and shot (30 min).

The procedure was applied to a sample of 12 male players taking part in the provincial soccer championship. Their anthropometric data are shown in Table 1.

Table 1. Anthropometric data

\begin{tabular}{lcc}
\hline \multicolumn{1}{c}{ Subjects $(\mathrm{n}=12)$} & M & SD \\
\hline Age $($ year $)$ & 11.5 & 0.79 \\
Height $(\mathrm{cm})$ & 152.8 & 2.95 \\
Weight $(\mathrm{Kg})$ & 44.6 & 2.11 \\
BMI $\left(\mathrm{Kg} / \mathrm{m}^{2}\right)$ & 19.1 & 1.42 \\
\hline
\end{tabular}

The tests performed by young players are three: Dexterity circuit (Harre), Precision shooting and Ball control, which can detect the qualitative abilities of young players. The tests were performed by 12 young soccer players, members of a soccer school in the category under twelve, on a 7-a-side soccer field measuring 65 meters long and 40 meters wide. Furthermore, as they were under-age, their parents signed a consent stating that they were taking responsibility and authorised their children to perform several tests.

All the collected data were expressed as average \pm SD for: height, weight, body mass index, Dexterity circuit (Harre), Precision shooting and Ball control in order to check the normal distribution of several variables (KS Test). The analysis involves the use of Student's t-Test to check the differences between pre- and post-training for the three tests conducted, as well as the relative percentages of improvement. The significant differences were fixed at $\mathrm{p}<0.05$. All statistical analyses were performed using the Dell's statistical software 13.2.

\section{Testing general motor skills}

- Dexterity circuit (Harre): is used to assess the result of combining various coordination skills. The time taken to complete the entire route is recorded (Figure 1). The subject starts standing towards the mat, flips forwards, runs towards the medicine ball and heads for obstacle 1, skips it and then passes it downstairs and again the ball obstacle 2 - ball - obstacle 3 - ball - finish line. When the subject turns, the ball should always be on their right side and should not be touched, while the somersault should only be done once after departure.
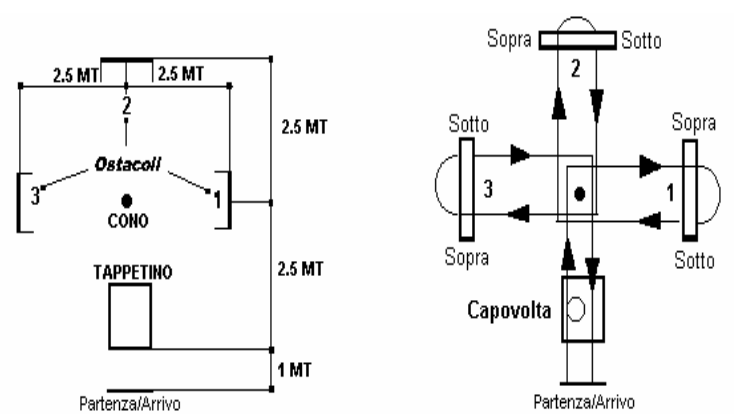

Figure 1. Dexterity circuit

\section{Testing specific motor skills}

- Precision shooting: 6 skittles are lined up at a distance of 1 meter and mark the soccer areas at 6-8-10-12-14 meters (Figure 2). The space between the central pins is 3 points, those adjacent -2 points, the side -1 point, and zero points - the external parts. The student kicks the ball firmly trying to make as many points as possible. Three attempts are made for 3 different distances (10-12-14 meters). Each student must perform the 3 kicks from the same distance one after the other, and then will go to the next distance when all students have made their 3 attempts. 
International Proceedings of Human Motricity/ ICPESK 2019

Supplementary Issue of Discobolul - Physical Education, Sport and Kinetotherapy Journal, 2019

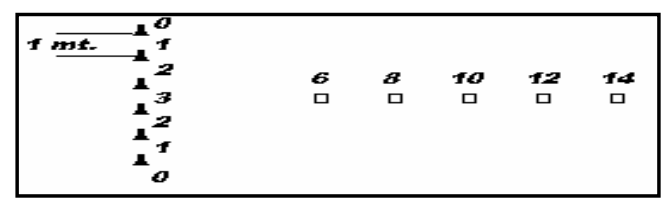

Figure 2. Precision shooting

- Ball control: A corridor is defined as 20 meters long and 1.50 meters wide (Figure 3). Each player starts with no start signal, with the ball placed on the starting line, and drives the ball in a straight line as quickly as possible. On completion, the ball must be stopped inside the square drawn at the end of the corridor. The ball must not leave the corridor and, if it comes out, it must be returned to the point where it has come out. Each student takes 2 tests with an interval of about 3-4 minutes. The time is recorded in hundredths of a second from the first touch of the ball to the moment of stopping it in the final square, and the best score in the two tests is retained.

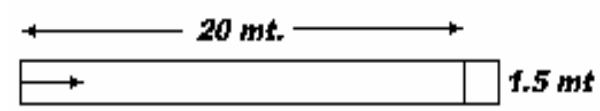

Figure 3. Ball control

\section{Results}

The results show that there are significant improvements between pre-test and post-test (after four weeks). In the Dexterity circuit test, there is a significant difference, as shown in Table 3. In the Precision shooting test, there is also a significant difference, as shown in Table 5. In the Ball control test, there is a significant difference too, as shown in Table 7. These tests analyse and assess the performance improvement, allowing coaches to monitor the training process and design the training load for effective performance. Table 2 shows the times achieved by each individual player in the two tests involving the execution of the Dexterity circuit and performed one month apart. The group average is $46.11 \mathrm{sec}$ in the first test and $43.27 \mathrm{sec}$ in the second test; therefore, we can say that there has been an average time improvement of $6.16 \%$ for the entire group. Table 4 shows the scores recorded by each individual player in the two tests involving the execution of the Precision shooting test and performed one month apart. Table 6 shows the times achieved by each individual player in the two tests involving the execution of the Ball control test and performed one month apart. The group average is 23.48 in the first test and 22.18 in the second test; therefore, we can say that the average time for the test has decreased, with an improvement of 5.54\%, which is however discreet, but after only one month, almost all students have improved their performance.

Table 2. Times recorded in the Dexterity circuit test

\begin{tabular}{lcc}
\hline & $1^{\text {st }}$ Test & $2^{\text {nd }}$ Test (after 4 weeks) \\
\hline 1 & 49.34 & 45.88 \\
2 & 42.77 & 39.93 \\
3 & 48.97 & 46.72 \\
4 & 50.86 & 50.55 \\
5 & 44.91 & 40.34 \\
6 & 53.52 & 51.22 \\
7 & 39.70 & 36.57 \\
8 & 44.83 & 41.36 \\
9 & 40.92 & 38.73 \\
10 & 45.28 & 41.12 \\
11 & 47.11 & 44.42 \\
12 & 45.11 & 42.42 \\
Average & $\mathbf{4 6 . 1 1}$ & $\mathbf{4 3 . 2 7}$ \\
\hline
\end{tabular}

Table 3. Difference between pre-test and post-test (Dexterity circuit) 
International Proceedings of Human Motricity/ ICPESK 2019

Supplementary Issue of Discobolul - Physical Education, Sport and Kinetotherapy Journal, 2019

\begin{tabular}{|c|c|c|c|c|c|c|c|c|}
\hline & \multicolumn{5}{|c|}{ Coupled differences } & \multirow[b]{3}{*}{$\mathrm{t}$} & \multirow[b]{3}{*}{$\mathrm{gl}$} & \multirow{3}{*}{$\begin{array}{l}\text { Sign. (two- } \\
\text { tailed) }\end{array}$} \\
\hline & \multirow[b]{2}{*}{ Average } & \multirow[b]{2}{*}{$\mathrm{SD}$} & \multirow{2}{*}{$\begin{array}{c}\text { Average } \\
\text { standard error }\end{array}$} & \multicolumn{2}{|c|}{$\begin{array}{l}95 \% \text { confidence } \\
\text { interval difference }\end{array}$} & & & \\
\hline & & & & Lower & Upper & & & \\
\hline $\begin{array}{l}\text { VAR01 } \\
\text { VAR02 }\end{array}$ & 2.83833 & 1.09165 & .31513 & 2.14473 & 3.53194 & 9.007 & 11 & .000 \\
\hline
\end{tabular}

Table 4. Points recorded in the Precision shooting test

\begin{tabular}{lcc}
\hline & $1^{\text {st }}$ Test & $2^{\text {nd }}$ Test (after 4 weeks) \\
\hline 1 & 11 & 17 \\
2 & 13 & 22 \\
3 & 18 & 19 \\
4 & 8 & 12 \\
5 & 17 & 19 \\
6 & 13 & 13 \\
7 & 19 & 25 \\
8 & 14 & 18 \\
9 & 20 & 24 \\
10 & 17 & 18 \\
11 & 14 & 17 \\
12 & 16 & 19 \\
Average & $\mathbf{1 5}$ & $\mathbf{1 8 . 5 8}$ \\
\hline
\end{tabular}

Table 5. Difference between pre-test and post-test (Precision shooting)

\begin{tabular}{|c|c|c|c|c|c|c|c|c|}
\hline & \multicolumn{5}{|c|}{ Coupled differences } & \multirow[b]{3}{*}{$\mathrm{t}$} & \multirow[b]{3}{*}{$\mathrm{gl}$} & \multirow{3}{*}{$\begin{array}{l}\text { Sign. (two- } \\
\text { tailed) }\end{array}$} \\
\hline & \multirow[t]{2}{*}{ Average } & \multirow[t]{2}{*}{ SD } & \multirow[t]{2}{*}{$\begin{array}{c}\text { Average } \\
\text { standard error }\end{array}$} & \multicolumn{2}{|c|}{$\begin{array}{l}95 \% \text { confidence } \\
\text { interval difference }\end{array}$} & & & \\
\hline & & & & Lower & Upper & & & \\
\hline $\begin{array}{l}\text { VAR01 } \\
\text { VAR02 }\end{array}$ & -3.58333 & 2.53909 & .73297 & -5.19659 & -1.97007 & -4.889 & 11 & .000 \\
\hline
\end{tabular}

Table 6. Times recorded in the Ball control test

\begin{tabular}{ccc}
\hline & $1^{\text {st }}$ Test & $2^{\text {nd }}$ Test (after 4 weeks) \\
\hline 1 & 25.56 & 23.88 \\
2 & 19.73 & 18.53 \\
3 & 23.34 & 21.62 \\
4 & 28.64 & 27.45 \\
5 & 24.28 & 24.34 \\
6 & 27.95 & 27.16 \\
7 & 19.84 & 17.88 \\
8 & 22.36 & 21.61 \\
9 & 20.58 & 19.18 \\
10 & 21.84 & 20.22 \\
11 & 23.21 & 21.18 \\
12 & 24.42 & 23.08 \\
Average & $\mathbf{2 3 . 4 8}$ & $\mathbf{2 2 . 1 8}$ \\
\hline
\end{tabular}

Table 7. Difference between pre-test and post-test (Ball control) 


\begin{tabular}{|c|c|c|c|c|c|c|c|c|}
\hline & \multicolumn{5}{|c|}{ Coupled differences } & \multirow[b]{3}{*}{$\mathrm{t}$} & \multirow[b]{3}{*}{$\mathrm{gl}$} & \multirow{3}{*}{$\begin{array}{l}\text { Sign. (two- } \\
\text { tailed) }\end{array}$} \\
\hline & \multirow[t]{2}{*}{ Average } & \multirow[t]{2}{*}{$\mathrm{SD}$} & \multirow[t]{2}{*}{$\begin{array}{c}\text { Average standard } \\
\text { error }\end{array}$} & \multicolumn{2}{|c|}{$\begin{array}{l}95 \% \text { confidence } \\
\text { interval difference }\end{array}$} & & & \\
\hline & & & & Lower & Upper & & & \\
\hline $\begin{array}{l}\text { VAR01 } \\
\text { VAR02 }\end{array}$ & 1.30167 & .59065 & .17051 & .92638 & 1.67695 & 7.634 & 11 & .000 \\
\hline
\end{tabular}

\section{Discussion and Conclusion}

The study analysed and assessed the improvement of motor and technical skills in soccer players through tests and the monitoring of the effects induced by 4 weeks of specific training. This allows coaches to monitor the training process and design the training load for effective performance. During this period, players mainly performed three types of exercises (three times per week): 6 vs. 6 games with up to two ball touches (30 min), circuits or exercises for the coordination skills $(30 \mathrm{~min}$ ) and exercises for the individual technique such as dribble, pass and shot (30 min).

Specific training hours per week:

- Fundamentals of individual technique: 1h 30'

- Circuit or exercises for the coordination skills: $1 \mathrm{~h} 30^{\prime}$

- Game situations or mini matches in confined spaces with two touches: 1h 30'

- Total hours per month: $18 \mathrm{~h} \mathrm{00'}$

After analysing and interpreting the results, we can confirm that all this is actually feasible, since most of the subjects have improved their skills and performance, although in a different and individual way. The statistical processing of data shows that, following the training sessions carried out during the four weeks, a decent increase has been recorded for each of the three tests (a general coordination test and two specific coordination tests). The use of tests allows having a very effective periodic control and, due to the result analysis and the feedback received, it is possible to relate performance to working strategies, and thus identify and make the best adjustments to the training programme.

The conclusion drawn is an invitation to further investigations in order to reach the scientific knowledge that must always be the basis of any training methodology.

\section{References}

Altavilla, G., Tafuri, D., \& Raiola, G. (2014). Some aspects on teaching and learning by physical activity. Sport $\begin{array}{llll}\text { Science, } & 7(1), & \text { Retrieved } & \text { from }\end{array}$ https://www.sposci.com/PDFS/BR0701/SVEE/04\%20CL\%2001\%20GA.pdf

Chiodera, P., Volta, E., Gobbi, G., Milioli, M. A., Mirandola, P., Bonetti, A., ... Vitale, M. (2008). Specifically designed physical exercise programs improve children's motor abilities. Scandinavian Journal of Medicine \& Science in Sports, 18(2), 179-187. https://doi.org/10.1111/j.1600-0838.2007.00682.x

Cirillo, G., Nughes, E., Acanfora, A., Altavilla, G., \& D'Isanto, T. (2016) Physical and sport education testing by quantitative and qualitative tools in assessment in senior school: A proposal. Sport Science, 9(Suppl. 1), 97101. Retrieved from https://www.cabdirect.org/cabdirect/abstract/20163259149

Dellal, A., Chamari, K., Wong, D. P., Ahmaidi, S., Keller, D., Barros, R., ... Carling C. (2011). Comparison of physical and technical performance in European soccer match-play: FA Premier League and La Liga. European Journal of Sport Science, 11(1), 51-59. https://doi.org/10.1080/17461391.2010.481334

Fisher, A., Reilly, J. J., Kelly, L. A., Montgomery, C., Williamson, A., Paton, J. Y., \& Grant, S. (2005). Fundamental movement skills and habitual physical activity in young children. Medicine \& Science in Sports \& Exercise, 37(4), 684-688. https://doi.org/10.1249/01.MSS.0000159138.48107.7D

Hughes, M., \& Bartlett, R. (2002). JSS - Editorial of the special edition on performance analysis. International Journal of Performance Analysis in Sport, 2(1), 104-106. https://doi.org/10.1080/24748668.2002.11868264

Mathisen, G. E., \& Danielsen, K. H. (2014). Effects of speed exercises on acceleration and agility performance in 13-year-old female soccer players. Journal of Physical Education and Sport, 14(4), 471-474. DOI: 10.7752/jpes.2014.04071 
Polidoro, L., Bianchi, F., Di Tore, P.A., \& Raiola, G. (2013). Futsal training by video analysis. Journal of Human Sport and Exercise, 8(2), 290-296. http://dx.doi.org/10.4100/jhse.2012.8.Proc2.31

Raiola, G. (2012). Motor learning and didactics into physical education and sport documents in middle school first cycle of education in Italy. Journal of Physical Education and Sport, 12(2), 157-163. Retrieved from http://efsupit.ro/images/stories/vol_12_2_Art_25.pdf

Raiola, G., \& Rago, V. (2014). Preliminary study on effects of HIIT-high intensity intermittent training in youth soccer players. Journal of Physical Education and Sport, 14(2), 148-150. DOI:10.7752/jpes.2014.02023

Safrit, M. J. (1990). Introduction to measurement in physical education and exercise science ( $2^{\text {nd }}$ ed.). St. Louis: Times Mirror/Mosby College.

Serrano, J., Shahidian, S., Sampaio, J., \& Leite, N. (2013). The importance of sports performance factors and training contents from the perspective of futsal coaches. Journal of Human Kinetics, 38, 151-160. https://dx.doi.org/10.2478\%2Fhukin-2013-0055 